\title{
Effect of Extraction Time and Temperature on Total Flavanoid Contents of Petai Belalang (Leucaena leucocephala) Seed Pretreated by Enzymatic Hydrolysis
}

\author{
Nor Hanimah Hamidi*, Nurul Athirah Mohd Alwi, Haishwari Tarmalingam, \\ Siti Sabirah Ani Kutty and Siti Nur Nadzmiah Mohd Nor
}

Faculty of Chemical and Process Engineering Technology, Universiti Malaysia Pahang, Lebuhraya Tun Razak, 26300 Gambang, Kuantan, Pahang, Malaysia

\begin{abstract}
The abundant availability of Leucaena leucocephala (petai belalang) in Malaysia was one of the contributing factors of this research. The phytochemicals obtained from this plant will contribute towards many fields mainly medicine and it becomes more favorable as compared to the modern medicines used these days. Diseases such as cancer, high blood pressure and diabetes are very crucial, and it occurs frequently among all ages of citizens in Malaysia. Therefore, phytochemicals in this plant can be a great substitute of modern medicines. However, lignin is known to interfere with the cell wall polysaccharides digestion, and hence considered as an anti-quality component in forages. To improve phytochemicals extraction, an effective degradation method of lignin is in demand. Thus, the goal of the present study was to investigate the feasibility of using enzymatic hydrolysis by laccase from Trametes versicolor (LTV) to breakdown lignin using mild reaction condition. To clarify the effect of enzymatic hydrolysis, a preliminary study on the percentage of lignin removal was conducted that taking the effect of LTV concentration, incubation temperature and time into consideration. The results were then used to analyze total flavonoid contents (TFC) of L.leucocephala seed after the

ARTICLE INFO

Article history:

Received: 08 December 2020

Accepted: 15 April 2021

Published: 31 July 2021

DOI: https://doi.org/10.47836/pjst.29.3.08

$\overline{\text { E-mail addresses: }}$

nhanimah@ump.edu.my (Nor Hanimah Hamidi)

athirahalwi93@gmail.com (Nurul Athirah Mohd Alwi)

haishwari_tarmalingam@yahoo.com (Haishwari Tarmalingam)

sitinorsabirah96@gmail.com (Siti Sabirah Ani Kutty)

nurnadzmiah@gmail.com (Siti Nur Nadzmiah Mohd Nor)

* Corresponding author

extraction by using microwave-assisted hydrodistillation (MAHD) method. In view of this, extraction temperature and time were varied. TFC was estimated by UVVIS spectrophotometer for quantification by using quercetin as standard. The result emerge from this study showed that the TFC was high in the extraction temperature of $60^{\circ} \mathrm{C}$ in $12 \mathrm{~min}$ with an average of 1639
\end{abstract}


$\mathrm{mgQE} /$ g.d.w and the lowest TFC was recorded at $30^{\circ} \mathrm{C}$ with $677 \mathrm{mgQE} /$ g.d.w. Further analysis showed that enzymatic hydrolysis has assisted the extraction of flavonoids, thus, provided scientific method to extract flavonoid as an alternative therapy for various diseases.

Keywords: Enzymatic hydrolysis, flavonoid, Leucaena leucocephala, microwave assisted hydrodistillation, total flavonoid content (TFC)

\section{INTRODUCTION}

Flavonoids has been shown to have a profound effect on reducing oxidative stress and preventing and reversing cancer cell developments (Valko et al., 2007). Deposition of flavonoids within the cell wall was originally proposed to account for the poor extractability of flavonoids from some plant material interrupted and surrounded by a lignin matrix (Markam, 1972). Depending on the type of plant, most of plant materials consist of approximately 15 - 35\% of lignin. In L. leucocephala seed cell wall, antioxidant is embedded with these substances, which make it difficult to obtain pure flavonoids (Rachtanapun et al., 2012). However, most of the studies done on the extraction of flavonoid from L. leucocephala did not consider pretreatment process prior to the extraction. Thus, this method was proposed for a better yield of desired product.

Earlier, organosolv method (ethanol/water) was used to isolate lignin from $L$. leucocephala, where they elucidated its structural and thermal behaviour (Tejado et al., 2007). Later, various histological, histochemical and biochemical methods were used to study the structure, histochemistry and chemical composition of tension wood, opposite wood and normal wood of L. leucocephala (Pramod et al., 2013). In this study, lignin was isolated from the seed of $L$. leucocephala using fungal laccase (Trametes versicolor). In this study, the biological approach is preferable as compared to chemical approach to reduce the possibility of hydrocarbon chain breakage. It is best to be kept in mind that, flavonoids are very sensitive antioxidant. As for the extraction method, microwave-assisted hydrodistillation (MAHD) was used in this study. Previous studies have shown that MAHD has successfully extract the desired product whilst reducing costs, avoiding the use of additives and harmful solvents and improving the effectiveness of the process (Bustamante et al., 2016). As these compounds are very sensitive and specific, the temperature and time of extraction plays an important role on the quality and quantity of the extracts. Thus, the effect of these parameters was considered in this study.

\section{MATERIALS AND METHODS}

\section{Materials and Chemicals}

L. leucocephala seeds powder was used in this study. Prior to the extraction process, L. leucocephala pods were plucked from along Jalan Gambang, Kuantan, Pahang. 
Laccase from Trametes versicolor (CAS Number: 80498-15-3), quercetin hydrate (CAS Number: 849061-97-8); aluminium chloride $\left(\mathrm{AlCl}_{3}\right)$ reagent grade (CAS Number: 744670-0); and 2,2'-azino-bis-3-ethylbenzothiazoline-6-sulfonic acid diammonium salt (ABTS) (CAS Number: 30931-67-0) were purchased from Sigma-Aldrich (UK).

\section{Sample Preparation}

L. leucocephala seeds were separated from the pods, washed with tap water to remove debris and dried in an oven at $40^{\circ} \mathrm{C}$ overnight. After drying, the seeds were grinded in blender until fine powder was formed. The powder was kept in chiller $\left(2{ }^{\circ} \mathrm{C}\right)$ until the extraction or enzymatic hydrolysis were conducted.

\section{Enzymatic Hydrolysis}

Incubator was switched on at varied temperature $50-90{ }^{\circ} \mathrm{C}$, at $10{ }^{\circ} \mathrm{C}$ interval. $5 \mathrm{~g}$ of sample was soaked in ammonium acetate buffer $(0.1 \mathrm{M}, \mathrm{pH} 4.5)$ and ABTS solution (0.1 M). The effect of LTV concentration was analysed by addition of $250 \mu \mathrm{l}$ of different LTV concentration $(0.1,0.2,0.3,0.4$ and $0.5 \mathrm{U} / \mathrm{ml})$ and was incubated at $200 \mathrm{rpm}$ for $6 \mathrm{~h}$ at 60 ${ }^{\circ} \mathrm{C}$ in a $250 \mathrm{ml}$ Erlenmeyer flask (Hamidi, 2013). After designated reaction time (2-10 h, at $2 \mathrm{~h}$ interval), the mixture was left to cool at room temperature and filtered. The solid residue was washed with distilled water and oven-dried at room temperature for $24 \mathrm{~h}$. Black liquor separated from the solid residue was then fractionated by liquid-liquid extraction using methanol at ratio of 1:3, sample to solvent and further concentrated in rotary evaporator for the determination of lignin removal.

\section{Percentage of Lignin Removal}

To identify the best condition for enzymatic hydrolysis, One-Factor-at-One-Time (OFAT) procedure was done to determine the best condition for enzymatic hydrolysis of $L$. Leucocephala. Standard analytical procedures (ES ISO 302:2015) were used to identified percentage of lignin removal, based on three parameters (LTV concentration, incubation temperature and time) that may affect the hydrolysis. Therefore, Kappa lignin in raw and treated L.leucocephala were determined according to Kappa number TAPPI T 236 om99 and ES ISO 302:2015. Percentage of lignin removal was calculated using Equation 1 according to the standard analytical procedure:

$$
\text { Lignin removal }(\%)=\frac{\operatorname{Kappa} \text { lignin }\left(\frac{\mathrm{g}}{\mathrm{ml}}\right) \times 100}{\text { sample mass }(\mathrm{g}) \times \text { total volume of solution }(\mathrm{mL})}
$$




\section{Microwave assisted Hydrodistillation (MAHD)}

MAHD was conducted by using Milestone Ethos E. For the extraction of flavanoid, the chiller temperature and the microwave power were set on $16^{\circ} \mathrm{C}$ and $250 \mathrm{~W}$, respectively. The extraction period was varied between 12 - $60 \mathrm{~min}$, at $12 \mathrm{~min}$ interval (Jeyaratnam et al., 2016). $5 \mathrm{~g}$ of L.Leucocephala seed powder and $500 \mathrm{ml}$ deionized water was transferred into $1 \mathrm{~L}$ round bottom flask (RBF) (Kusuma \& Mahfud., 2017). The extractions were conducted at different extraction temperatures varied between $30-80{ }^{\circ} \mathrm{C}$, at $10^{\circ} \mathrm{C}$ interval. After extraction, the extract-solute mixture was filtered, and the extracts were collected for TFC determination.

\section{Determination of Total Flavonoids Content (TFC)}

UV-VIS spectrophotometry analysis of flavonoids content in L. leucocephala seed extracts requires $5 \mathrm{mg}$ of dried extract (solid) dissolved in $1 \mathrm{ml}$ deionized water was subjected to a general procedure for flavonoids quantification (Oyedemi et al., 2018). Quercetin was used as a standard and the UV detector was set at the wavelength of $415 \mathrm{~nm}$. The adsorbents values were obtained in a spectrophotometer after complexation with $\mathrm{AlCl}_{3}$ (Kiranmai et al., 2011). Absolute ethanol was used as blank for standard while deionized water was used as blank for samples. Since the extract is in liquid form, extracts volume that equivalent to $5 \mathrm{mg}$ dried extract as represent by Equation 2 for UV-vis analysis and was determined using density by implementing Equation 3.

$$
\begin{aligned}
& \frac{1}{\rho_{\text {extract }}}\left(\frac{m l}{m g}\right) \times 5 m g \\
& \rho_{\text {solution }}-\rho_{\text {solvent }}=\rho_{\text {extract }}
\end{aligned}
$$

Using the linear equation from standard calibration curve, the concentration (mgQE/ $\mathrm{ml}$ ) of flavonoid in analysed sample was determined. The total flavonoids content in extract was calculated by multiplying with volume of solvent used (ml) and divided by mass dry weight seed used (g.d.w) as presented in Equation 4.

$$
\mathrm{TFC}=\frac{\text { concentration }\left(\frac{\mathrm{mgQE}}{\mathrm{ml}}\right) \times \text { solvent volume }(\mathrm{ml})}{\text { mass dry weight }(\mathrm{g} . \mathrm{d} . \mathrm{w})}
$$

\section{RESULTS AND DISCUSSION}

\section{The Effect of Enzyme Hydrolysis on the Percentage of Lignin Removal}

In this investigation, the effect of LTV concentration, reaction temperature and reaction time were considered. 
The effect of LTV concentration on the treatment was investigated using different concentration of $\operatorname{LTV}(0.15,0.25,0.35,0.45,0.55$ and $0.65 \mathrm{mg} / \mathrm{ml})$. The highest percentage of lignin removal was found to be $71.5 \%$ at $0.55 \mathrm{mg} / \mathrm{ml}$ of LTV. It is apparent from Figure 1(a) that percentage of lignin removal was increased as the enzyme concentration increases due to the rate of enzymatic reactions that was also increased (Ishmael et al., 2016). However, there was no increase of lignin removal was observed associated with the increment of LTV concentration to $0.65 \mathrm{mg} / \mathrm{ml}$. This result support the idea that the rate of enzymatic reaction increasing proportional to the laccase concentration. This result may be explained by the fact that laccases are known as blue-copper phenoloxidase that catalyse one-electron oxidation by removing one electron, generating phenoxy-free radical products which can lead to polymer cleavage (Pérez et al., 2002). Thus, by increasing LTV concentration, it could facilitate oxidation process and wide range of polymer cleavage. This led to the breakdown of lignin structure, hence increase the percentage of lignin removal.

To assess the optimum incubation temperature that may affect lignin removal, varied temperatures were employed ranged between $30-100{ }^{\circ} \mathrm{C}$, at $10^{\circ} \mathrm{C}$ interval. The optimum incubation temperature for enzymatic hydrolysis was at $60^{\circ} \mathrm{C}$ as shown in Figure $1(\mathrm{~b})$, which remove $72.38 \%$ lignin. The present finding seems to be consistent with other researches which found that $60{ }^{\circ} \mathrm{C}$ was the optimum temperature for LTV activity (de Carvalho et al., 1999; Monteiro \& de Carvalho., 1998). Further increase in incubation temperature revealing steady decline in the percentage of lignin removal, which indicate the denaturation of the enzyme. However, lignin removal can still be observed even though the incubation temperature was increased up to $100{ }^{\circ} \mathrm{C}$ as more than $70 \%$ of lignin was removed. It is appearing favourable that LTV showed an outstanding stability towards higher temperature. The heat tolerance of laccase was suggested to be due to high glycosylation rate that protect laccase from heat denaturation (Slomczynski et al. 1995; Fukushima \& Kirk, 1995).

Incubation time is a contributing factor for optimum lignin removal in enzymatic hydrolysis. Therefore, incubation time between $2-10 \mathrm{~h}$, at $2 \mathrm{~h}$ intervals was deployed to demonstrate the effect. Figure 1(c) shows that there has been a gradual increase in percentage of lignin removal at the first $2 \mathrm{~h}$ but steady drop after $6 \mathrm{~h}$ of incubation. What can be clearly seen in Figure 1 is the highest percentage of lignin removal, $71 \%$ for seeds were found at $6 \mathrm{~h}$ of incubation. Prior studies that have noted the delignification process tends to increase with time of contact between enzyme and substrate until the enzyme activity is slow (Ishmael et al., 2016). In this study, $6 \mathrm{~h}$ of incubation was found to be optimum time taken for achieving maximum rate of reaction due to inactivation of enzyme and possibility of repolymerization at reaction time between 8 to $10 \mathrm{~h}$ which complies with literature (Gierer, 1985; Monteiro \& de Carvalho, 1998). According to these data, we can infer that $6 \mathrm{~h}$ of reaction time was optimum for delignification process. 


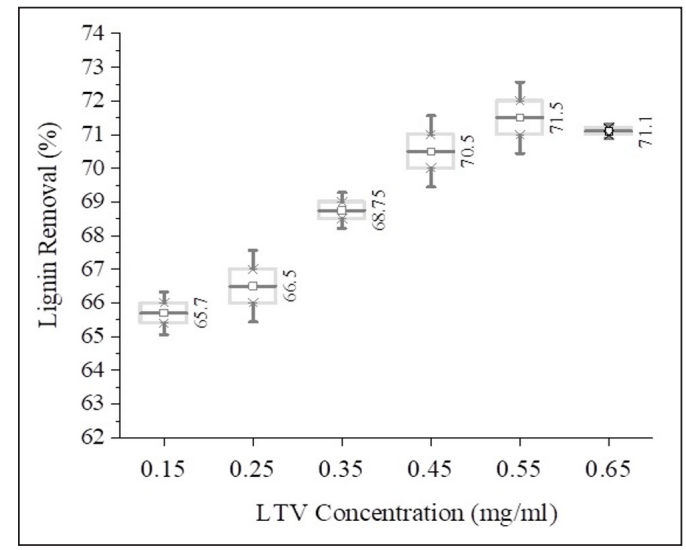

(a)

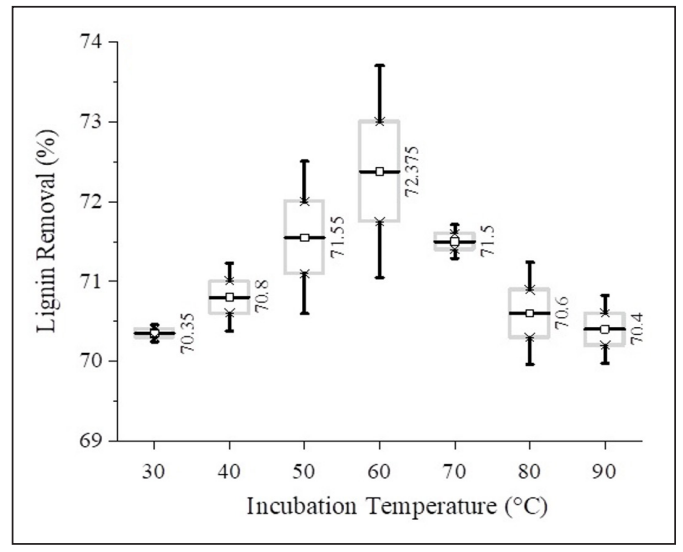

(b)

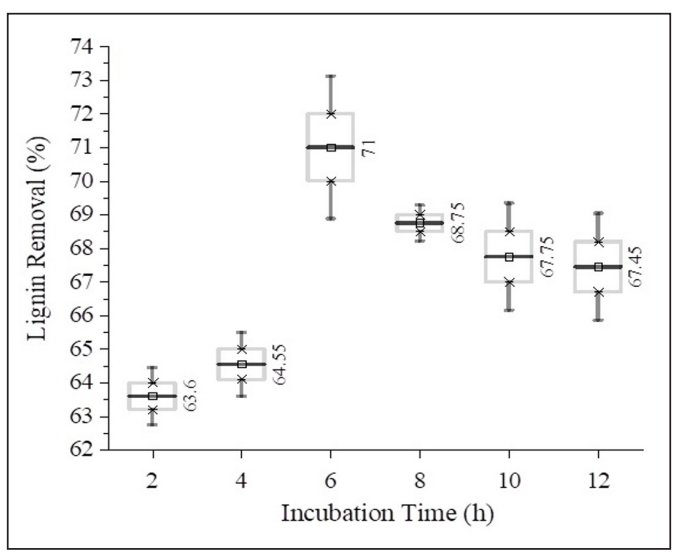

(c)

Figure 1. Box plot format graphic showing the effect of (a) LTV concentration, (b) Incubation temperature, (c) Incubation time, with mean, maximum/minimum values of standard deviation. By using One-Way ANOVA analysis by OriginPro $2019 \mathrm{~b}$ at the 0.05 level, the sample means are significant with p-value of $1.61 \times 10^{-4}, 2.5 \times 10^{-2}$ and $1.6 \times 10^{-3}$, respectively.

\section{The Effect of Extraction Time on Total Flavanoid Content (TFC)}

Extraction by MAHD at different times $(0,12,24,32,48$, and $60 \mathrm{~min})$ was conducted to encounter the most efficient time to collect the highest amount of flavanoid. It is apparent from Figure 2 that the highest TFC was observed at 12 min of extraction with the content of $1670 \mathrm{mgQE} / \mathrm{g}$.dw compared to the lowest TFC approximately $124 \mathrm{mgQE} / \mathrm{g}$.dw at $60 \mathrm{~min}$. This finding further supported by the extracted sample with the presence of enzymatic hydrolysis revealed the same trend whereby flavonoid yield was highest at 12 min of extraction with TFC of $1943 \mathrm{mgQE} / \mathrm{g}$.dw meanwhile at $60 \mathrm{~min}$ the yield excessively decreased to $273 \mathrm{mgQE} / \mathrm{g}$.dw. Both control and hydrolysed sample depicted similarity with highest flavonoid content at $12 \mathrm{~min}$ of extraction. These samples revealed about $85 \%$ decrease of flavonoid yield as the extraction were conducted for an hour. The results are in 
line with Rezvanpanah et al. (2008) which reported that the optimum extraction time using MAHD was 6 min and 12 min for Satureja hortensis and Satureja Montana, respectively. This finding further supported by Farhat et al. (2011) who found that less time was required for essential oil extraction thoroughly from orange peels via MAHD extraction that only required $12 \mathrm{~min}$ if compared to traditional hydrodistillation (HD) that takes $40 \mathrm{~min}$ to be completed. Apart from classical conductive heating methods, microwave extraction methods can heat the entire sample almost simultaneously and at a higher rate (Hashmi \& Kim, 2003). When sample is exposed to heat at long period, particles may degrade causing the extract to be not productive due to more inactive compounds extracted (Dent et al., 2013). Therefore, with usage of MAHD, extraction efficiency can be achieved intensively within a short period of time consuming less energy and time proving that this extraction process can be both economic and environmentally friendly. Extraction period of only about 12 min were enough to achieve the highest yield of flavonoids from seeds of this plant.

Previous experiment revealed that enzymatic hydrolysis on seeds of L.leucocephala was able to promote delignification at optimum reaction condition ( $6 \mathrm{~h}$ of incubation time, $60{ }^{\circ} \mathrm{C}$ incubation temperature and $0.55 \mathrm{mg} / \mathrm{ml}$ LTV concentration). In view of this, effect of enzymatic hydrolysis was considered to enhance TFC. The result obtained from the study are presented in Figure 2. Interestingly, there was a significant positive correlation between enzymatic hydrolysis and TFC in which TFC was high in the presence of enzymatic hydrolysis compared with absence of this process.

The obtained result was in line with the study made on effect of hydrolysis in antioxidant extraction whereby laccase-mediator system has appeared to enhance the hydrolysis of lignin (Moilanen et al., 2014). In addition, from research done by Draganescu et al.

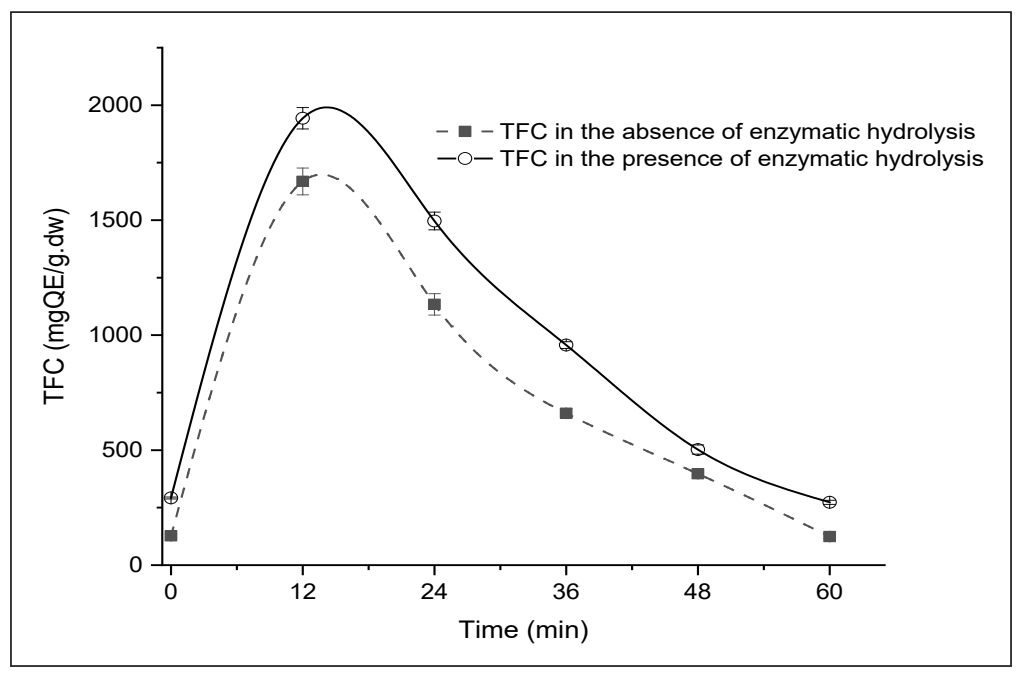

Figure 2. The effect of extraction time on total flavanoid content (TFC) of L. leucocephala seed extract with presence and absence of enzymatic hydrolysis. By using One-Way ANOVA analysis by OriginPro 2019b at the 0.05 level, the sample means are significant with p-value of $2.73 \times 10^{-17}$ and $1.63 \times 10^{-15}$, respectively. 
(2017), it was found that the contents of oligomers in the flaxseed extract after hydrolysis with lignin peroxidases increased significantly based on the chromatographic peak height when compared with the raw lyophilized flaxseed extract, indicating an advanced, but incomplete process. After enzymatic hydrolysis, the active ingredients may also dissolve more easily in the extraction medium (Pytkowska et al., 2013). These results support the idea that enzymatic hydrolysis approach is particularly suitable to enhance the extraction of natural compounds for optimum yield.

\section{The Effect of Extraction Temperature on Total Flavanoid Content (TFC)}

The plot in Figure 3 shows the interaction between extraction temperature and TFC at the fixed 12 min extraction time. It was observed that the value of TFC increased as the temperature increased from $30^{\circ} \mathrm{C}$ to $60^{\circ} \mathrm{C}$. In contrast, increasing the extraction temperature beyond $60^{\circ} \mathrm{C}$ resulted in the decreased of TFC values. It is encouraging to compare Figure 3 with that found by Azahar et al. (2017) whose found out that the flavonoid content increased as the temperature approached $70^{\circ} \mathrm{C}$, and gradually decline as the temperature rise above its optimum temperature. A likely explanation is that higher temperature cause plant tissue rupture, thus solvent was easily to dissolved and degrade active compounds in the plant (Azahar et al., 2017; Yoswathana, 2013). It is apparent from Figure 3 that the best temperature for flavonoid extraction is $60^{\circ} \mathrm{C}$ regardless of whether the seeds were treated or not prior to extraction. The concentrations of flavonoids were approximately $1639 \mathrm{mgQE} / \mathrm{g} . \mathrm{dw}$ and $1389 \mathrm{mgQE} / \mathrm{g}$.dw, respectively. The extract comprising the least

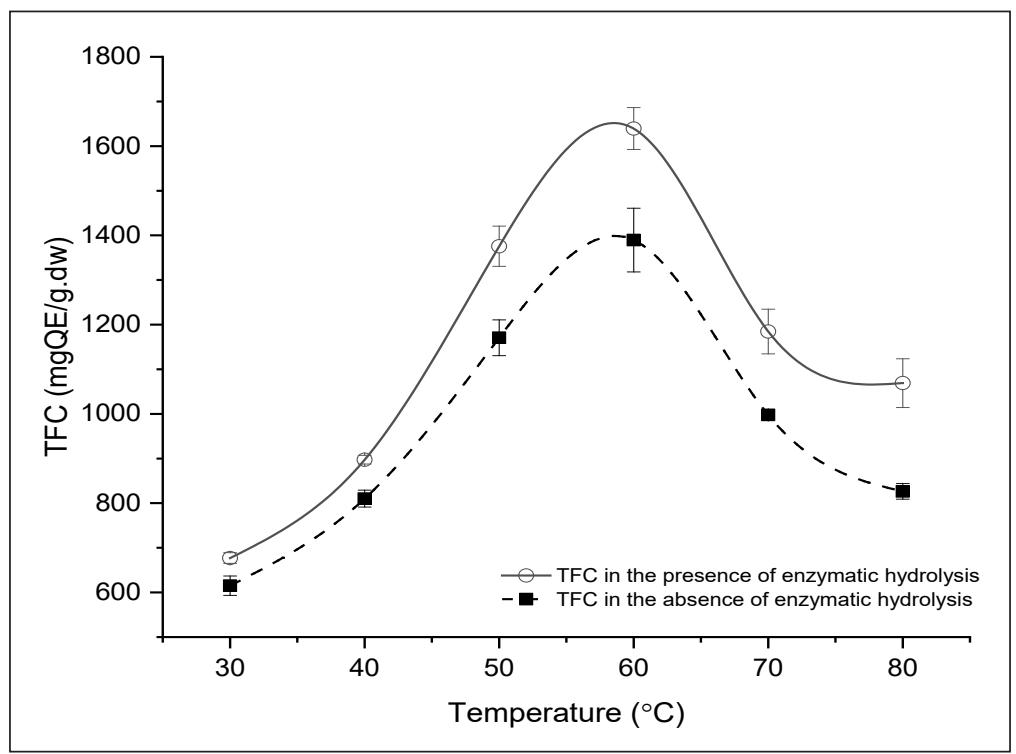

Figure 3. The effect of extraction temperature on total flavanoid content (TFC) of L. leucocephala seed extract with presence and absence of enzymatic hydrolysis. By using One-Way ANOVA analysis by OriginPro $2019 \mathrm{~b}$ at the 0.05 level, the sample means are significant with p-value of $2.9 \times 10^{-11}$ and $8.5 \times 10^{-11}$, respectively. 
concentration of flavonoid is in the extraction that was performed at $30^{\circ} \mathrm{C}$ with $677 \mathrm{mgQE} / \mathrm{g}$. $\mathrm{dw}$ for pretreated extracts and $615 \mathrm{mgQE} / \mathrm{g}$.dw for control. Since L.leucocephala seeds for the pretreated extracts experienced enzymatic hydrolysis at $60^{\circ} \mathrm{C}$ for $6 \mathrm{~h}$ ahead of extraction, the chances are, more flavonoids were extracted if compared to the extraction process without pretreatment. It is appears that enzymatic hydrolysis of complex lignin in L.leucocephala seed enhances the release of flavanoids while preserving their biological potential (Hammed et al., 2013).

\section{CONCLUSION}

The efficiency of extraction of flavonoids from L. leucocephala depended on the extraction time and temperature by MAHD. The extraction was also enhanced by enzymatic hydrolysis prior to extraction. The relevance of this process is clearly supported by current findings that suggest enzymatic hydrolysis by laccase from Trametes versicolor increase percentage of lignin removal, thus TFC value was also increased. The extraction by MAHD is a green method, because it limits the consumptions of toxic solvents and energy by running the process in $12 \mathrm{~min}$ at $60^{\circ} \mathrm{C}$. It is supported by green pretreatment process which employed the use of laccase to delignifying L. leucocephala in $6 \mathrm{~h}$ at $60^{\circ} \mathrm{C}$. Moreover, flavonoids are characterized as high in antioxidant contents which indicates a great potential to be applied in dietary supplement industry.

\section{ACKNOWLEDGEMENT}

The authors would like to thank the Ministry of Higher Education for providing financial support under Fundamental Research Grant Scheme (FRGS) No. FRGS/1/2018/TK02/ UMP/02/19 (University reference RDU190139) and Universiti Malaysia Pahang for laboratory facilities as well as additional financial support under Internal Research grant RDU170345.

\section{REFERENCES}

Azahar, N. F., Gani, S. S. A., \& Mokhtar, N. F. M. (2017). Optimization of phenolics and flavonoids extraction conditions of Curcuma zedoaria leaves using response surface methodology. Chemistry Central Journal, 11(1), 1-10. https://doi.org/10.1186/s13065-017-0324-y

Bustamante, J., van Stempvoort, S., García-Gallarreta, M., Houghton, J. A., Briers, H. K., Budarin, V. L., Matharu, A. S., \& Clark, J. H. (2016). Microwave assisted hydro-distillation of essential oils from wet citrus peel waste. Journal of Cleaner Production, 137, 598-605. https://doi.org/10.1016/j.jclepro.2016.07.108

de Carvalho M. E., Monteiro M. C., \& Sant'Anna, G. L. (1999). Laccase from Trametes versicolor: Stability at temperature and alkaline conditions and its effect on biobleaching of hardwood kraft pulp. Applied Biochemistry and Biotechnology, 77(79), 723-33. https://doi.org/10.1385/abab:79:1-3:723 
Dent, M., Dragović-Uzelac, V., Penić, M., Brñić, M., Bosiljkov, T., \& Levaj, B. (2013). The effect of extraction solvents, temperature and time on the composition and mass fraction of polyphenols in dalmatian wild sage (Salvia officinalis L.) extracts. Food Technology and Biotechnology, 51(1), 84-91.

Draganescu, D., Dodi, G., Stoica, I., \& Popa, M. I. (2017). Hydrolysis studies of flaxseed extract by high performance liquid chromatography. Cellulose Chemistry and Technology, 51(9-10), 803-811.

Farhat, A., Fabiano-Tixier, A. S., Maataoui, M. E., Maingonnat, J. F., Romdhane, M., \& Chemat, F. (2011). Microwave steam diffusion for extraction of essential oil from orange peel: Kinetic data, extract's global yield and mechanism. Food Chemistry, 125(1), 255-261. https://doi.org/10.1016/j.foodchem.2010.07.110

Fukushima, Y., \& Kirk, K. (1995). Laccase component of the Ceriporiopsis subvermispora lignin-degrading system. Applied and Environmental Microbiology, 61, 872-876.

Gierer, J. (1985). Chemistry of delignification - Part 1: General concept and reactions during pulping. Wood Science and Technology, 19(4), 289-312.

Hamidi, N. H. (2013) Enzymatic depolymerization of lignin by laccases (PhD thesis). University of Nottingham, UK.

Hammed, A. M., Jaswir, I., Amid, A., Alam, Z., Asiyanbi-H, T. T., \& Ramli, N. (2013). Enzymatic hydrolysis of plants and algae for extraction of bioactive compounds. Food Reviews International, 29(4), 352-370. https://doi.org/10.1080/87559129.2013.818012

Hashmi, I., \& Kim, J. G. (2003). Comparison of degradation studies in a biosimulator by continuous cultivation of Pseudomonas and indigenous microorganisms with varied dissolved oxygen concentrations. International Journal of Environment and Pollution, 19(2), 123-138. https://doi.org/10.1504/IJEP.2003.003744

Ishmael, U. C., Rashid, S. S., \& Ahmad, N. S. S. N. W. (2016, September 18). Optimization of laccase enzyme pretreatment process parameters of empty fruit bunches ( EFB ) using one-factor-at-a-time (OFAT). In Proceedings of the National Conference of Postgraduate Research 2016. Universiti Malaysia Pahang, Malaysia.

Jeyaratnam, N., Nour, A. H., \& Akindoyo, J. O. (2016). The potential of microwave assisted hydrodistillation in extraction of essential oil from Cinnamomum Cassia (cinnamon). ARPN Journal of Engineering and Applied Sciences, 11(4), 2179-2183.

Kiranmai, M., Kumar, C. B. M., \& Ibrahim, M. (2011). Comparison of total flavanoid content of Azadirachta indica root bark extracts prepared by different methods of extraction. Research Journal of Pharmaceutical, Biological and Chemical Sciences, 2(3), 254-261.

Kusuma, H. S., \& Mahfud, M. (2017). Microwave-assisted hydrodistillation for extraction of essential oil from patchouli (Pogostemon cablin) leaves. Periodica Polytechnica Chemical Engineering, 61(2), 82-92. https://doi.org/10.3311/PPch.8676

Markam, K. R. (1972). A novel flavone-polysaccharide compound from Monoclea forsteri. Phytochemistry, 11(6), 2047-2053. https://doi.org/10.1016/S0031-9422(00)90171-7.

Moilanen, U., Kellock, M., Várnai, A., Andberg, M., \& Viikari, L. (2014). Mechanisms of laccase-mediator treatments improving the enzymatic hydrolysis of pre-treated spruce. Biotechnology for Biofuels, 7(1), 1-13. https://doi.org/10.1186/s13068-014-0177-8 
Monteiro, M. C., \& de Carvalho, M. E. (1998). Pulp bleaching using laccase from Trametes versicolor under high temperature and alkaline conditions. Applied Biochemistry and Biotechnology - Part A Enzyme Engineering and Biotechnology, 983, 70-72. https://doi.org/10.1007/978-1-4612-1814-2_91

Oyedemi, B. O., Oyedemi, S. O., Chibuzor, J. V, Ijeh, I. I., Coopoosamy, R. M., \& Aiyegoro, A. O. (2018). Pharmacological evaluation of selected medicinal plants used in the management of oral and skin infections in Ebem-Ohafia District, Abia State, Nigeria. The Scientific World Journal, 2018, 1-16. https:// doi.org/10.1155/2018/4757458

Pérez, J., Muñoz-Dorado, J., De La Rubia, T., \& Martínez, J. (2002). Biodegradation and biological treatments of cellulose, hemicellulose and lignin: An overview. International Microbiology, 5(2), 53-63. https://doi. org/10.1007/s10123-002-0062-3

Pramod, S., Rao, K. S., \& Sundberg, A. (2013). Structural, histochemical and chemical characterization of normal, tension and opposite wood of Subabul (Leucaena leucocephala (lam.) de wit.). Wood Science and Technology, 47(4), 777-796. https://doi.org/10.1007/s00226-013-0528-9

Pytkowska, K., Bregisz, M., Majewski, S., Ratz-Łyko, A., \& Arct, J. (2013). Effect of enzymatic hydrolysis on the antioxidant properties of alcoholic extracts of oilseed cakes. Food Technology and Biotechnology, 51(4), 539-546.

Rachtanapun, P., Luangkamin, S., Tanprasert, K., \& Suriyatem, R. (2012). Carboxymethyl cellulose film from durian rind. LWT - Food Science Technology 48(1), 52-58. https://doi.org/10.1016/j.lwt.2012.02.029

Rezvanpanah, S., Rezaei, K., Razavi, S. H., \& Moini, S. (2008). Use of microwave-assisted hydrodistillation to extract the essential oils from Satureja hortensis and Satureja montana. Food Science and Technology Research, 14(3), 311-314. https://doi.org/10.3136/fstr.14.311

Slomczynski, D., Nakas, J. P., \& Tanenbaum, S. W. (1995) Production and characterization of laccase from Botrytis cinerea. Applied and Environmental Microbiology, 6, 907-912.

Tejado, A., Peña, C., Labidi, J., Echeverria, J. M., \& Mondragon, I. (2007). Physico-chemical characterization of lignins from different sources for use in phenol-formaldehyde resin synthesis. Bioresource Technology, 98(8), 1655-1663. https://doi.org/10.1016/j.biortech.2006.05.042

Valko, M., Leibfritz, D., Moncol, J., Cronin, M. T. D., Mazur, M., \& Telser, J. (2007). Free radicals and antioxidants in normal physiological functions and human disease. International Journal of Biochemistry and Cell Biology, 39(1), 44-84. https://doi.org/10.1016/j.biocel.2006.07.001

Yoswathana, N. (2013). Optimization of $\mathrm{ScCO}_{2}$ extraction of rambutan seed oil using response surface methodology. International Journal of Chemical Engineering and Applications, 4(4), 187-190. https:// doi.org/10.7763/IJCEA.2013.V4.291 
